\title{
Б.Н. ЗИМИН И ОТЕЧЕСТВЕННАЯ СОЦИАЛЬНО-ЭКОНОМИЧЕСКАЯ ГЕОГРАФИЯ: К 90-ЛЕТИЮ СО ДНЯ РОЖДЕНИЯ
}

\author{
(C) 2020 г. Д. Л. Лопатников* \\ Институт географии РАН, Москва, Россия \\ *e-mail: imartos@mail.ru \\ Поступила в редакцию 05.06.2019 г. \\ После доработки 05.07.2019 г. \\ Принята к публикации 03.10.2019 г.
}

\begin{abstract}
В трудах Б.Н. Зимина заложены основные принципы и подходы к географическому мирохозяйственному анализу. Один из ключевых: взаимодополнение отраслевого и территориального подходов. Им выявлены ключевые закономерности размещения промышленности в зрелой рыночной среде, влияние на сдвиги в размещении промышленности интеграционных процессов. Европейскую интеграцию он рассматривал как периодическое, циклическое явление и как процесс, имеющий рациональные размеры и предельные величины эффективности функционирования. Опираясь на четко сформулированные критерии (объем ВВП, превышение ВНП над внутренним спросом более чем на 1/3, узкая, ориентированная, прежде всего, на внешние рынки отраслевая структура хозяйства, повышенная доля нематериального производства), Б.Н. Зимин разработал теорию “Малых стран”. Из его работ по географии “черного рынка” выросло полноценное направление экономико-географических исследований. Оценивая перспективы постсоциалистической трансформации хозяйства России, Зимин доказывал, что она будет проходить не по автаркическому пути, а по пути реинтеграции в мирохозяйственную систему и будет детерминирована конъюнктурой мировых рынков в рамках глобальной экономики.
\end{abstract}

Ключевые слова: мировое хозяйство, размещение промышленности, рыночная среда, интеграция, малые страны, география “черного рынка”, постсоциалистическая трансформация хозяйства России

DOI: $10.31857 / \mathrm{S} 2587556620010136$

В отличие от многих своих современников и нынешних коллег по цеху, Борис Николаевич Зимин не интересовался званиями, регалиями, своей “публикационной активностью" и тому подобным тленом. Он просто был увлечен географией.

Борис Николаевич родился 25 декабря 1929 г. Ему повезло с родителями. Они одарили своего отпрыска брутальной внешностью в сочетании с контрастирующей с ней врожденной рафинированной интеллигентностью и аналитическим складом ума.

С 1949 по 1954 г. Зимин учился на географическом факультете МГУ. Он был незаурядным студентом и поражал своих сокурсников и преподавателей замечательной памятью и широчайшим кругозором. И.А. Витвер говорил о подающем большие надежды студенте: “Зимин знает все”.

С 1957 по 1961 г. Борис Николаевич был сотрудником Госэкономсовета СССР. Сведения об этой работе Зимина предельно скупы, что связано, в частности, с тем, что он имел дело с закрытыми документами. Можно только отметить, что этот период по-своему был очень полезен: помню, Борис Николаевич говорил, что он имел доступ к богатой статистике как по социалистическим, так и капиталистическим странам. В эти же годы у него наладились научные связи с Институтом географии АН СССР. В 1961 г. Г.Д. Кулагин пригласил Б.Н. Зимина в организуемый отдел технико-экономических исследований ИГ АН (затем отдел географии мирового хозяйства, ныне - лаборатория географии мирового развития). Зимин работал в этом подразделении Института географии РАН с 1962 по 1974 и с 1978 по 1995 г. Перерыв был связан с его занятостью в редакции географии Большой Советской Энциклопедии, которой он заведовал в середине 1970-х.

Как человек увлекающийся и, одновременно, обладающий энциклопедическими знаниями, он успел оставить яркий след в самых различных направлениях географии. Назову главные: отраслевая и территориальная структура хозяйства США и ФРГ, теория “малых развитых стран”, теория размещения промышленного производства в развитой рыночной среде, география отраслей и рынков мирового хозяйства, география теневой экономики, экологическая география. И во всех этих областях, ставших сегодня полноценными самостоятельными направлениями географических изысканий, Зимин был мощным генератором идей.

У людей, фонтанирующих собственными мыслями, в отличие от тех, кто обладает другим даром: красиво компоновать заимствованные цитаты, не всегда формируются стройные системные блоки. Это обратная сторона увлеченности и свободы науч- 
ного творчества. Но этот “изъян” был во многом купирован соратниками, коллегами и последователями как при жизни, так и уже после его ухода, которые принимали деятельное участие в подготовке его рукописей к печати. Такая была замечательная корпоративная этика в отделе.

Будучи человеком архищедрым вообще и на идеи в частности, он опубликовал много работ в соавторстве. Какие имена: В.М. Гохман, А.П. Горкин, Ю.Г. Липец, Л.В. Смирнягин, С.Б. Шлихтер, Г.А. Приваловская, С.С. Артоболевский...

Б.Н. Зимин всегда уделял большое внимание преподаванию и воспитанию учеников, сформировал свою школу в географии промышленности и географии мирового хозяйства. Его аспирантами и учениками в разные годы были Л.А. Аксенова, Т.А. Галкина, Д.Л. Лопатников, С.В. Одессер, Л.М. Синцеров, В.Н. Стрелецкий.

В 1995-м Бориса Николаевича Зимина не стало. Его прах упокоился на кладбище Донского монастыря.

Что он оставил географической науке?

В начале 1990-х годов вышла в свет серия внешне неприметных сборников "География мирового хозяйства" под редакцией Б.Н. Зимина и В.М. Ма-нусова [1]. Как в конце прошлого века, так и сегодня начинать изучение географии мирового хозяйства нужно с этих сборников. Они базовые. В них заложены основные принципы и подходы к географическому мирохозяйственному анализу. Зимин вместе с соавторами смогли снять проблему противопоставления отраслевого и территориального подхода и искусно показать, как их грамотно гармонизировать. А ведь это была тема, темная тень которой витала над советской экономической географией с 1920-х годов. Нелишне вспомнить противостояние "отраслевиков" и “районщиков", а в лицах: В.Э. Дена и Н.Н. Баранского, закончившееся политическим разгромом “деновщины” и репрессиями. Борис Николаевич сам был отраслевик-промышленник. При этом на любую отрасль он смотрел исключительно сквозь призму пространственного анализа, то есть как географ. И этому он учил своих учеников.

Промышленности Борис Николаевич уделял особое внимание. Он формировался как ученый в индустриальную эпоху, когда именно промышленность была символом прогресса, а уровень ее развития главным мерилом уровня развития стран в целом. Достопамятная "Перестройка" открыла возможности для разворота экономико-географических исследований от выполнения госзаданий Госплана СССР к осмыслению законов пространственной организации различных отраслей хозяйства в рыночной экономике, которая в то время в нашей стране толькотолько зарождалась. Изыскания Зимина в 1980-х годах в этом направлении были новаторскими. На примере стран Западной, капиталистической Европы, Борис Николаевич выявил ключевые закономерности размещения промышленности в зрелой рыночной среде, влияние на сдвиги в размещении про- мышленности интеграционных процессов [4]. Европейскую интеграцию он рассматривал как периодическое, циклическое явление и как процесс, имеющий рациональные размеры и предельные величины эффективности функционирования. За тридцать лет до “Брексита” Борис Николаевич пророчески писал о “пределах интеграции”, доказывая, что по мере расширения Общеевропейского экономического пространства первоначально положительный баланс между выгодами и издержками будет меняться на отрицательный, и интеграция из “локомотива Европы” может стать тормозом ее развития.

Опыт Западной Европы Зимину был нужен, прежде всего, для сравнительного экономикогеографического анализа возможных путей развития России и постсоветского пространства. Перспективы постсоциалистической России Зимин оценивал, опираясь не на возможности автаркичного пути с опорой на собственные силы, а на конъюнктуру мировых рынков в рамках глобальной экономики. Зимин оказался прав, так как именно эта конъюнктура определила реальный вектор развития России в последующие десятилетия, качество ее реинтеграции в мировую экономическую систему с известными проблемами “сырьевого придатка", “ресурсного проклятья" и др. Борис Николаевич не втягивался в политизированные споры глобалистов и антиглобалистов и не подстраивал свое видение географии под собственные политические воззрения. Он смотрел на мир, убирая за скобки свои внутренние симпатии и антипатии. Это редкий дар.

Бориса Николаевича всегда привлекали нетривиальные темы. Одна из таких - теневая экономика. Из его работ по географии “черного рынка” выросло полноценное направление экономико-географических исследований. Прошедший школу Госплана СССР и знающий цену статистике, он успел воспользоваться по максимуму горбачевской “гласностью” и ельцинской открытостью информации. Используя как отечественную, так и зарубежную статистику и литературу, Зимин не только показал масштабы и отраслевую структуру теневой экономики в нашей стране. Он дал ретроспективную панораму этого особого сектора всего мирового хозяйства от его зарождения в эпоху античности до конца прошлого века. Какое это увлекательное чтение!..

Особое место в наследии Б.Н. Зимина занимает теория “развитых малых стран”. Это действительно теория, далеко выходящая за рамки формулировки типологических признаков данной группы государств. Опираясь на четко сформулированные критерии (объем ВВП, превышение ВНП над внутренним спросом более чем на $1 / 3$, узкая, ориентированная, прежде всего, на внешние рынки отраслевая структура хозяйства, повышенная доля нематериального производства) [2], Зимин делает ряд концептуальных выводов. Среди них, например, то, что малые высокоразвитые 
страны Западной Европы гораздо удачнее приспособились к изменчивой послевоенной экономической конъюнктуре, чем большие страны. Ни одна малая страна не потеряла своего значения в мировом хозяйстве и не снизила существенно своего относительного душевого дохода, как это случилось с рядом больших стран, например, Великобританией [6].

И в заключение немного личных воспоминаний. В последние несколько лет жизни Борис Николаевич редко выходил из дому и у себя на неухоженной холостяцкой квартире с потрясающим видом из окна на Яузу и Кремль проводил серию семинаров по экономической географии для аспирантов и молодых сотрудников Института географии. Я, к сожалению, из-за плотного графика работы не мог их посещать, но Борис Николаевич нашел выход - предложил прочесть для меня одного (!) в удобное для меня время курс лекций по экономической и социальной географии Зарубежной Европы, на которой я специализировался. Я ходил к Борису Николаевичу ежене- дельно в течение семестра. Конспекты этих лекций - память и благодарность на всю жизнь.

\section{СПИСОК ЛИТЕРАТУРЫ}

1. География мирового хозяйства. Глобальные проблемы современности: Сб. / под ред. Б.Н. Зимина. М.: Минобразования РСФСР, 1991. 284 с.

2. Зимин Б.Н. Малые высокоразвитые страны Западной Европы - теоретические итоги исследований // Изв. РАН. Сер. геогр. 1993. № 2. С. 95-104.

3. Зимин Б.Н., Липеи, Ю.Г. Конструктивный анализ теорий размещения капиталистического производства / Методологические аспекты современной конструктивной географии. М.: ИГ АН СССР, 1985. C. 100-115.

4. Зимин Б.Н. Новые тенденции в размещении промышленности Западной Европы // Изв. АН СССР. Сер. геогр. 1972. № 6. С. 95-101.

5. Зимин Б.Н. Изменение территориально-отраслевой структуры промышленности // Сдвиги в географии населения и хозяйства стран Западной Европы / отв. ред. В.М. Гохман. М.: Наука, 1984. С. 26-42.

6. Зимин Б.Н. Размещение производства в рыночной среде (из трудов) / сост. А.П. Горкин, Ю.Г. Липец. М.: Альфа-М, 2003. 176 с.

\title{
B.N. Zimin and Russian Socio-Economic Geography: to the 90th Anniversary of the Birth
}

\author{
D. L. Lopatnikov \\ Institute of geography, Russian Academy of Sciences, Moscow, Russia \\ \# e-mail: imartos@mail.ru
}

Received June 5, 2019; revised July 5, 2019; accepted October 3, 2019

\begin{abstract}
In the works of B.N. Zimin laid the basic principles and approaches to geo-graphical world economic analysis. One of the key ones is the complementarity of sectoral and territorial approaches. He identified the key patterns of industry placement in a mature market environment, the influence of integration processes on shifts in industry placement. He considered European integration as a periodic, cyclical phenomenon and as a process having rational dimensions and finite values of functioning efficiency. Based on clearly formulated criteria (GDP volume, excess of GNP over domestic demand by more than 1/3, narrow sectoral structure of the economy focused primarily on foreign markets, increased share of non-domestic production), B.N. Zimin developed the theory of "Small countries". From his work on the geography of the "black market" grew a fullfledged direction of economic and geographical research. Assessing the prospects of post-socialist transformation of the Russian economy Zimin proved that it will not take place in an autarkic way, but in the context of reintegration in world economic system and will be determined by the situation in world markets in the global economy.
\end{abstract}

Keywords: world economy, industrial location, market environment, integration, "Small countries", geography of the "Black market", post-socialist transformation of the Russian economy

\section{REFERENCES}

1. Geografiya mirovogo khozyaistva. Global'nye problemy sovremennosti [Geography of the World Economy. Present Global Problems]. Zimin B.N., Ed. Moscow: Minobrazovaniya RSFSR, 1991. 284 p.

2. Zimin B.N. Small highly developed countries of Western Europe - theoretical results of research. Izv. Akad. Nauk, Ser. Geogr., 1993, no. 2, pp. 95-104. (In Russ.).

3. Zimin B.N., Lipets Y.G. The structural analysis of location theories of capitalist production. In Metodologicheskie aspekty sovremennoi konstruktivnoi geografii [Methodological Aspects of Modern Constructive Geography]. Moscow: Inst. Geogr. Akad. Nauk SSSR, 1985, pp. 100-115. (In Russ.).
4. Zimin B.N. New trends in the location of industry in Western Europe. Izv. Akad. Nauk, Ser. Geogr., 1972, no. 6, pp. 95-101. (In Russ.).

5. Zimin B.N. Changes in the territorial and sectoral structure of industry. In Sdvigi v geografii naseleniya $i$ khozyaistva stran Zapadnoi Evropy [Shifts in the Geography of Population and Economy of Western Europe]. Gokhman V.M., Ed. Moscow: Nauka Publ., 1984, pp. 26-42. (In. Russ.).

6. Zimin B.N. Razmeshchenie proizvodstva v rynochnoi srede [Location of Production in Market Environment]. Gorkin A.P., Lipets Yu.G., Eds. Moscow: Al'fa-M Publ., 2003. $176 \mathrm{p}$. 